\title{
Performance of Custom-Made Very High Temperature Thermocouples in the Advanced Gas Reactor Experiment AGR-5/6/7 during Irradiation in the Advanced Test Reactor
}

\author{
A. J. Palmer*, R. S. Skifton, M. Scervini, D. C. Haggard, W. D. Swank \\ * Idaho National Laboratory, \\ joe.palmer@inl.gov
}

\begin{abstract}
The Advanced Gas Reactor-5/6/7 (AGR-5/6/7) experiment is the fourth and final experiment in the AGR experiment series and will serve as the formal fuel qualification test for the TRISO fuels under development by the U.S. Department of Energy. Certain locations in this experiment reach temperatures higher than any of the previous AGR tests, up to $1500^{\circ} \mathrm{C}$. Such extreme temperatures create unique challenges for thermocouple-based temperature measurements. Hightemperature platinum-rhodium thermocouples (Types $S, R$, and B) and tungsten-rhenium thermocouples (Type $C$ ) suffer rapid decalibration due to transmutation of the thermoelements from neutron absorption. For lower temperature applications, previous experience with Type $K$ thermocouples in nuclear reactors have shown that they are affected by neutron irradiation only to a limited extent. Similarly, Type $\mathbf{N}$ thermocouples, which are more stable than Type $\mathrm{K}$ at high temperatures, are only slightly affected by neutron fluence. Until recently, the use of these nickel-based thermocouples was limited when the temperature exceeds $1050^{\circ} \mathrm{C}$ due to drift related to phenomena other than nuclear irradiation. Recognizing the limitations of existing thermometery to measure such high temperatures, the sponsor of the AGR-5/6/7 experiment supported a development and testing program for thermocouples capable of low drift operation at temperatures above $1100^{\circ} \mathrm{C}$. High Temperature Irradiation Resistant Thermocouples (HTIR-TCs) based on molybdenum/niobium thermoelements have been under development at Idaho National Laboratory (INL) since circa 2004. A step change in accuracy and long-term stability of this thermocouple type has been achieved as part of the AGR-5/6/7 thermometry development program. Additionally, long-term testing $(9000+\mathrm{hrs})$ at $1250^{\circ} \mathrm{C}$ of the Type $\mathrm{N}$ thermocouples utilizing a customized sheath developed at the University of Cambridge has been completed with low drift results. Both the improved HTIR and the Cambridge Type $\mathbf{N}$ thermocouple types have been incorporated into the AGR-5/6/7 test, which began irradiation in February 2018 in INL's Advanced
\end{abstract}

Paper submitted 05-15-2019.

This work was supported by the U.S. Department of Energy under DOE Idaho Operations Office Contract DE-AC07-05ID14517. Accordingly, the U.S. Government retains and the publisher, by accepting the article for publication, acknowledges that the U.S. Government retains a nonexclusive, paid-up, irrevocable, worldwide license to publish or reproduce the published form of this manuscript or allow others to do so, for U.S. Government purposes.

This information was prepared as an account of work sponsored by an agency of the U.S. Government. Neither the U.S. Government nor any agency thereof, nor any of their employees, makes any warranty, express or implied, or assumes any legal liability or responsibility for the accuracy, completeness, or usefulness of any information, apparatus, product, or process disclosed, or
Test Reactor. Both the improved HTIR and Cambridge Type N thermocouples have exhibited (apparent) low-drift performance during the 170 days of irradiation conducted to date; however, their open circuit failure rates have been quite high $(>50 \%)$. One of the HTIR thermocouples operated stably at $>1450^{\circ} \mathrm{C}$ for more than 80 days, which we believe is the highest temperature any thermocouple has operated without significant drift in a high neutron flux environment. A description of the performance of the entire AGR-5/6/7 thermocouple set, consisting of 54 thermocouples, is provided in this paper.

Keywords-In-Pile Instrumentation, Material and Test Reactors, High-temperature Irradiation, Thermocouples, Thermocouple Testing.

\section{INTRODUCTION}

$\mathrm{T}$ he Advanced Test Reactor (ATR) at Idaho National Laboratory (INL) is being used to conduct an experiment series designated the Advanced Gas Reactor (AGR) tristructural isotopic (TRISO) fuel experiments to qualify this fuel's irradiation performance for High Temperature Gas Reactor (HTGR) applications. The final experiment in this series is denoted AGR-5/6/7. As with the previous AGR experiments, it consists of multiple capsules stacked vertically and with separate temperature-control gas blends for each capsule. It is an instrumented-lead type experiment, with online active temperature control and fission-product monitoring of the effluent gas [1].

Each of the five AGR-5/6/7 capsules consist of a graphite fuel holder with holes drilled axially to accommodate the $12.4 \mathrm{~mm}$ diameter $\times 25 \mathrm{~mm}$ long fuel compacts. Metal-sheathed thermocouples and gas lines are inserted into small holes drilled into the graphite holders, as illustrated in Figs. 1 and 2.

represents that its use would not infringe privately owned rights. References herein to any specific commercial product, process, or service by trade name, trademark, manufacturer, or otherwise, does not necessarily constitute or imply its endorsement, recommendation, or favoring by the U.S. Government or any agency thereof. The views and opinions of authors expressed herein do not necessarily state or reflect those of the U.S. Government or any agency thereof.

A. J. Palmer, R.S. Skifton, D.C. Haggard, and W. D. Swank are with the Idaho National Laboratory, P.O. Box 1625, MS 3840, Idaho Falls, ID, USA 38415-3840. The corresponding author's email address is joe.palmer@inl.gov.

M. Scervini is with the University of Cambridge, Department of Material Science and Metallurgy, 27 Charles Babbage Road, CB3 OFS, Cambridge, UK. 


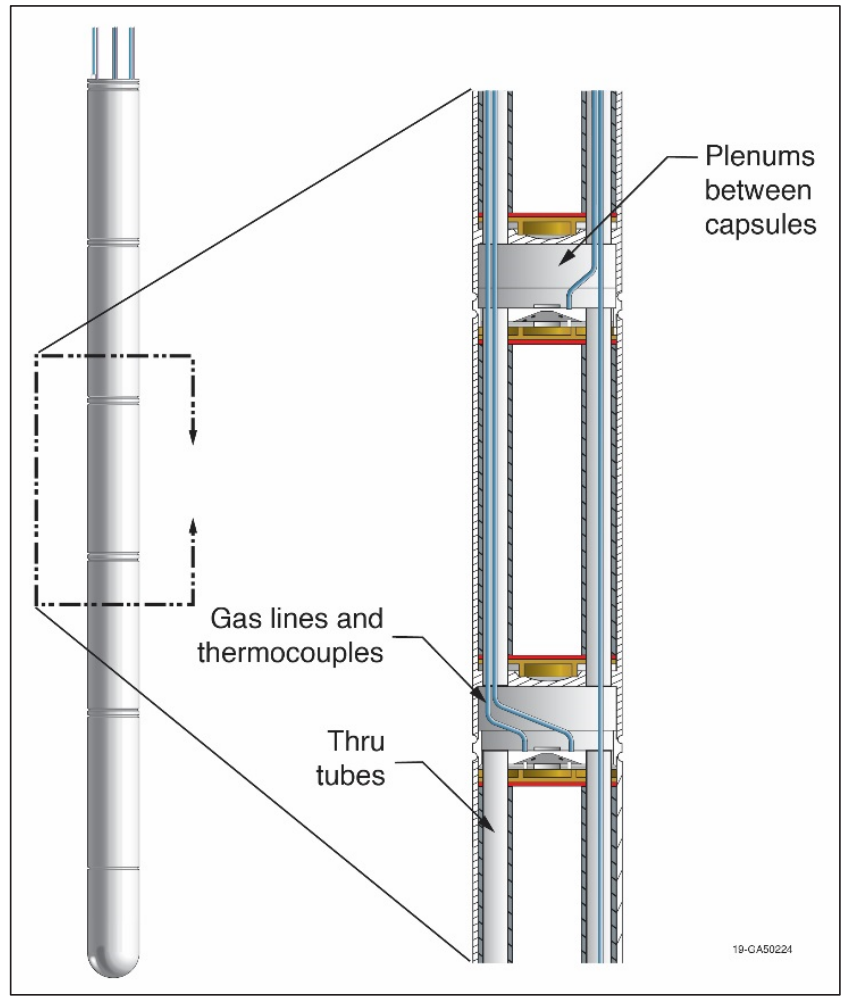

Fig. 1. Elevation view of typical AGR fuel experiment.

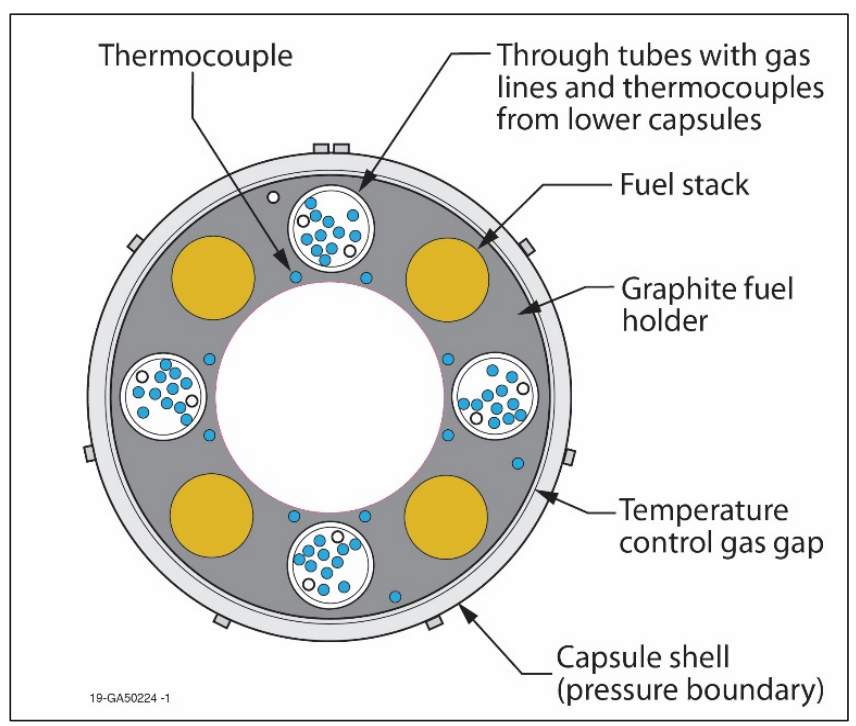

Fig. 2. Cross-section view of AGR-5/6/7 fuel experiment (capsules 2, 4, 5).

AGR-5/6/7 is a combination of three experiments that were envisioned at the beginning of the program. The conditions created in the five capsules making up this test serve as the formal fuel qualification irradiations (AGR-5/6) and the margin test (AGR-7). The purpose of the margin test is to demonstrate that there is a substantial margin between the highest fuel temperature in an operating HTGR and the temperature at which fuel particle failure rate becomes unacceptable.

Temperature measurement has been a critical-but challenging - aspect of all of the AGR experiments because of the high temperatures involved. Commonly used hightemperature commercial thermocouples-such as platinumrhodium (Types S, R, and B) and tungsten-rhenium (Type C)- suffer dramatic drift as a result of neutron-induced transmutation [2, 3]. These thermocouples types, which are used routinely for high-temperature measurements outside of the reactors, are only used in very special circumstances for reactor experiments. Type $\mathrm{K}$ and Type $\mathrm{N}$ thermocouples are affected to only a limited extent $[4,5]$ by neutron irradiation.

However, the use of these nickel-based thermocouples is limited when the temperature exceeds $1050^{\circ} \mathrm{C}$ due to drift arising from minor alloying elements migrating from the thermocouple's metal sheath to the thermoelements. This change in the composition of the thermolements results in significant decalibration of the signal.

Because it was designed as the fuel qualification and margin test, the AGR-5/6/7 experiment requires measurements in locations with higher operating temperatures than any of the previous experiments. These measurement points experience temperatures up to $1500^{\circ} \mathrm{C}$, with many locations above $1200^{\circ} \mathrm{C}$. Recognizing the limitations of existing thermometry to measure such high temperatures, the AGR-5/6/7 program sponsor supported a development and testing program for thermocouples capable of low-drift operation at temperatures greater than $1100^{\circ} \mathrm{C}$. This program included additional development of high-temperature irradiation-resistant thermocouples (HTIR-TCs) based on molybdenum/niobium thermoelements, which have been studied at INL since circa $2004[6,7]$. As a result of this development program, a step change in accuracy and long-term stability of this thermocouple type was achieved [8, 9]. Additionally, long-term furnace testing $(9000+\mathrm{hrs})$ at $1250^{\circ} \mathrm{C}$ of Type $\mathrm{N}$ thermocouples utilizing a customized sheath developed at the University of Cambridge [10] (called herein CAMB Type N) were completed, also with low-drift results [9].

\section{AGR-5/6/7 THERMOCOUPLES INSTALLATION}

\section{A. Thermocouple Types and Distribution}

The calculated temperature measurement range for the AGR-5/6/7 thermocouples encompassed a range from 700 to $1500^{\circ} \mathrm{C}$. It was determined to divide this broad range into three smaller temperature ranges, as follows:

- $\quad<1000^{\circ} \mathrm{C}$

- $\quad 1000-1250^{\circ} \mathrm{C}$

- $\quad 1250-1500^{\circ} \mathrm{C}$.

For the $<1000^{\circ} \mathrm{C}$ range, standard Type $\mathrm{N}$ thermocouples are adequate. For the $1000-1250^{\circ} \mathrm{C}$ range, it was determined that both HTIR-TCs and CAMB Type $\mathrm{N}$ would be used. Only HTIR-TCs have the capability of surviving at temperatures above $1300^{\circ} \mathrm{C}$, and so only this type was designated for the $1250-1500^{\circ} \mathrm{C}$ range.

For AGR-5/6/7, the "standard Type N" thermocouples incoporated an Inconel 600 sheath and $\mathrm{MgO}$ or Spinel insulation. The CAMB Type $\mathrm{N}$ thermocouples incoporated a proprietary high nickel alloy sheath $[9,10]$ and $\mathrm{MgO}$ insulation. The HTIR-TCs incorporated a pure $\mathrm{Nb}$ sheath and $\mathrm{Al}_{2} \mathrm{O}_{3}$ insulation with thermoelements composed of Mo alloyed with La (0.5-1.0\%), and Niobium alloyed with $\mathrm{P} \leq 0.1 \%$, Ta $\leq 0.3 \%$.

Because of the high temperatures involved in AGR-5/6/7, 
and because two of the three previous AGR tests had ended with a very reduced thermocouple set (for AGR-2, not one thermocouple was operating at the end of the test), it was thought prudent to incorporate as many thermocouples as possible. The number of thermocouples is limited primarily by the number of cables that can be passed through the thru-tubes of the top capsule. Given the space constraints on the size of the thru-tubes, the AGR-5/6/7 project settled on a 54 thermocouple budget. This budget was twice the number of thermocouples installed in any previous AGR experiment.

As discussed below, capsules near the bottom of the train were expected to experience higher failure rates, and higher temperature capsules would also experience higher failure rates. Based on these criteria, the 54 thermocouple budget was distributed as shown in Table I.

In accordance with the ATR numbering convention, capsules in the AGR-5/6/7 test train are numbered from the bottom up; therefore, capsule 1 is the bottom capsule, and capsule 5 is the

TABLE I

AGR-5/6/7 THEMOCOUPLE Allocation

\begin{tabular}{|c|c|c|c|c|}
\hline Cpsule ID & Std TCs & CAMB TCs & HTIR-TCs & Totals \\
\hline Cap 5 & 6 & 0 & 0 & 6 \\
\hline Cap 4 & 6 & 0 & 0 & 6 \\
\hline Cap 3 & 4 & 7 & 6 & 17 \\
\hline Cap 2 & 8 & 0 & 0 & 8 \\
\hline Cap 1 & 1 & 7 & 9 & 17 \\
\hline Totals & 25 & 14 & 15 & 54 \\
\hline
\end{tabular}

top one. Capsule 3 represents the margin test and it was designed for the highest fuel temperatures $\left(1300-1500^{\circ} \mathrm{C}\right)$; therefore, a large number was allocated-17. Capsule 1 was designed for the second highest temperatures and is the bottom capsule, so it was also given an allocation of 17. Capsules 2, 4, and 5 were designed for temperatures in decreasing order. Since capsule 2 is lower in the test train, and was designed for a marginally higher temperature than capsules 4 and 5, it was assigned 8 thermocouples. The remaining 12 were evenly divided between the two upper capsules.

\section{B. Protective Sleeves}

In the AGR-5/6/7 experiment, each thermocouple was installed inside a protective sleeve. This was done for two reasons: (1) to protect the thermocouple sheaths from carburization and premature failure; and (2) to protect the $\mathrm{SiC}$ layer of the TRISO-coated fuel particles from first-row transition elements, such as $\mathrm{Cr}, \mathrm{Fe}$, and $\mathrm{Ni}$. The furnace testing program revealed that the selection of protective sleeves could affect drift performance. For example, in the $1200-1250^{\circ} \mathrm{C}$ range, the CAMB Type $\mathrm{N}$ thermocouples drifted about $5^{\circ} \mathrm{C}$ per $1000 \mathrm{hrs}$ when surrounded by $\mathrm{Nb}$ sleeves [11], but only $2.5^{\circ} \mathrm{C}$ per 1000 hrs with Mo sleeves [9]. This drift is due to solid state diffusion of the sleeve material through the TC sheath and insulation and into the thermoelements, thus changing their composition. Although, Mo was confirmed superior to $\mathrm{Nb}$ as a protective sleeve material, it is also very prone to cracking. Mo was not used in the highest temperature regions to surround CAMB Type N TCs to avoid the risk of a crack allowing Ni from the Cambridge TC sheaths to migrate to the SiC-coated fuel particles. For these locations, $\mathrm{ZrO}_{2}$ sleeves were used instead.

\section{Contributors to Thermocouple Failures}

A need exists to effect a seal where the thermocouples penetrate the capsule heads; as such, different methods are possible. For the AGR experiment series, brazing was used, primarily because of space constraints. Unfortunately, brazing creates a brittle area (as shown in Fig. 3), where the thermocouple sheath exits the capsule head, and this brittle region is prone to fracture. Fractures in this location have occurred from handling during assembly, and it is assumed that these locations are likely failure points during irradiation.

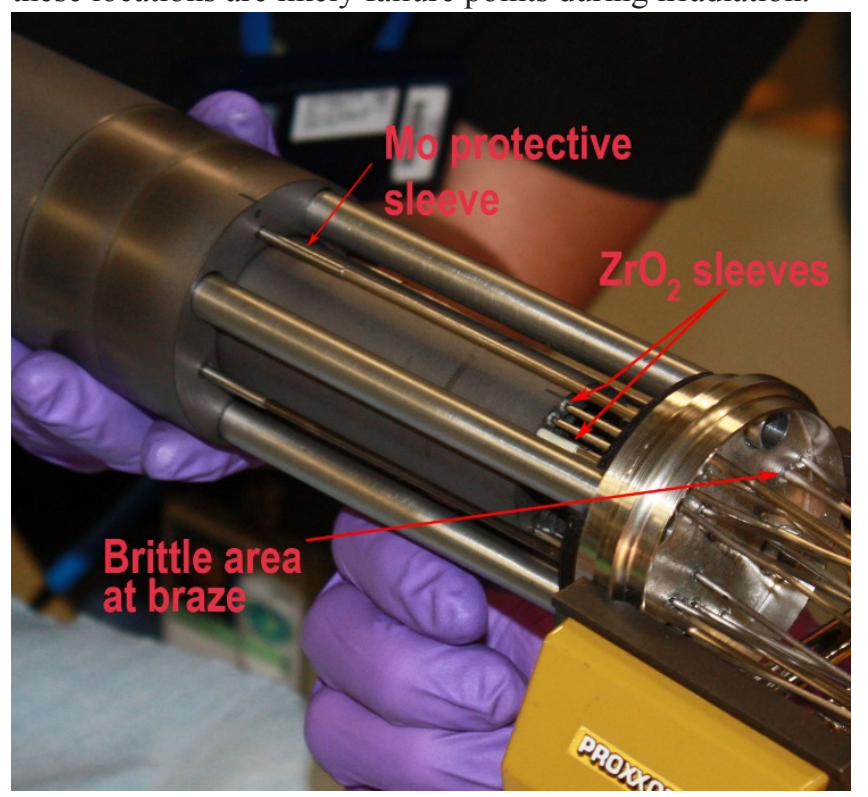

Fig. 3. Capsule 3 protective sleeves and brittle braze area.

All of the test trains in the AGR experiment series incorporated a similar design (i.e., a series of individual capsules stacked on top of each other with thermocouples from lower capsules passing through the bodies of upper capsules by means of small metallic conduits called thru-tubes). This design has the advantage of each capsule being a separate irradiation cell, with a separate gas blend and temperature control system. However, it has the disadvantage of requiring thermocouples from lower capsules to make a long perilous journey through small, hot conduits. Thermocouples from the bottom capsule have a heated length of almost $90 \mathrm{~cm}$ and experience thermal expansion-contractions on the order of 6-8 $\mathrm{mm}$ each time the reactor stops and starts. An examination of failure data from previous AGR experiments indicated that failures tended to occur from the bottom capsule up, confirming the proposition that thermal expansion was one of the main contributors to thermocouple failure.

The other large contributor to thermocouple failure is peak temperature experienced by the thermocouple. Table II is a temperature limit summary from a major thermocouple distributor [12]. Note that these limits are not the operational limits for Type $\mathrm{N}$ thermocouples (Type $\mathrm{N}$ thermocouples can operate up to near their melting point for short periods), but 
rather the recommended diameter for reliable long-term service.

\section{TABLE II}

RECOMMENDED SHEATH DIAMETER VS TEMPERATURE FOR MINERAL INSULATED THERMOCOUPLES

\begin{tabular}{|c|c|c|c|c|c|}
\hline Sheath & $0.032^{\prime \prime}$ & $0.040^{\prime \prime}$ & $0.062^{\prime \prime}$ & $0.093^{\prime \prime}$ & $0.125^{\prime \prime}$ \\
T/C Pia. & $0.8 \mathrm{~mm}$ & $1.0 \mathrm{~mm}$ & $1.6 \mathrm{~mm}$ & $2.4 \mathrm{~mm}$ & $3.2 \mathrm{~mm}$ \\
\hline $\mathrm{J}$ & $260(500)$ & $260(500)$ & $440(825)$ & $480(900)$ & $520(970)$ \\
\hline $\mathrm{K} \& \mathrm{~N}$ & $700(1290)$ & $700(1290)$ & $920(1690)$ & $1000(1830)$ & $1070(1960)$ \\
\hline
\end{tabular}

The sheath diameter of the thermocouples (all three designs) in the AGR-5/6/7 experiment was $1.6 \mathrm{~mm}$. Thermocouple diameters of $1.5 \mathrm{~mm}$ or $1.6 \mathrm{~mm}$ are very commonly used in high temperature reactor experiments - this size offers a good combination of flexibility and durability. However, according to Table II, temperatures above $920^{\circ} \mathrm{C}$ are not recommended for this size. The operating temperature of many of the AGR-5/6/7 Type $\mathrm{N}$ thermocouples exceed this recommended temperature for a $1.6 \mathrm{~mm}$ Type $\mathrm{N}$, so a relatively high failure rate is to be expected. As a practical matter, this is unavoidable for most experiments, as large sheath diameters, such as 3 or $4 \mathrm{~mm}$, are difficult to incorporate and tend to interfere with space allocated for specimens. In addition, large thermocouples are subject to considerable nuclear heating effects, which can raise the junction temperature well above its surroundings.

\section{AGR-5/6/7 THERMOCOUPLE IRRADIATION PERFORMANCE}

\section{A. Open Circuit Failure}

Table III tracks thermocouple failures in the AGR-5/6/7 experiment over the first three standard cycles and one short low-power cycle (163A). This represents approximately 170 days of full power irradiation, but only 155 days of full temperature operation. This is about one third of the planned irradiation period. The failure rate has been higher than expected. To begin with, five thermocouples were lost during assembly. The two samples lost in capsule 3-TC-3-8 and TC-3-16-were HTIR-TCs, which failed because of a manufacturing defect. The sheaths of these two thermocouples

TABLE III

SURVIVING THERMOCOUPLES BY CAPSULE AND IRRADIATION CYCLE

\begin{tabular}{|c|c|c|c|c|c|c|c|}
\hline \multicolumn{2}{|c|}{$\begin{array}{l}\text { Survivors by } \\
\text { Capsule/Type }\end{array}$} & $\begin{array}{l}\text { End of } \\
\text { Assem }\end{array}$ & $\begin{array}{l}\text { End of } \\
\text { Install }\end{array}$ & $\begin{array}{c}\text { End of } \\
162 B\end{array}$ & $\begin{array}{c}\text { End of } \\
163 A\end{array}$ & $\begin{array}{c}\text { End of } \\
164 A\end{array}$ & $\begin{array}{c}\text { End of } \\
164 B\end{array}$ \\
\hline Cap 5 & STD & 4 & 3 & 3 & 3 & 3 & 3 \\
\hline Cap 4 & STD & 5 & 4 & 4 & 4 & 4 & 4 \\
\hline \multirow{3}{*}{ Cap 3} & STD & 4 & 4 & 4 & 4 & 4 & 4 \\
\hline & CAMB & 7 & 5 & 5 & 5 & 2 & 2 \\
\hline & HTIR & 4 & 4 & 3 & 3 & 3 & 3 \\
\hline Cap 2 & STD & 8 & 8 & 8 & 8 & 6 & 3 \\
\hline \multirow{3}{*}{ Cap 1} & STD & 1 & 1 & 1 & 0 & 0 & 0 \\
\hline & CAMB & 7 & 7 & 6 & 6 & 3 & 1 \\
\hline & HTIR & 9 & 9 & 4 & 4 & 4 & 3 \\
\hline \multicolumn{2}{|l|}{$\begin{array}{l}\text { Total } \\
\text { Survivin }\end{array}$} & 49 & 45 & 38 & 37 & 29 & 23 \\
\hline
\end{tabular}

(pure $\mathrm{Nb}$ ) were extremely brittle and broke as they were being bent into the thru-tubes of capsule 4 . TC-5-6 broke at the braze during assembly, while TC-5-3 and TC-5-4 failed at the transition cup from strain on the cables as the top and bottom sections of the test train were pressed together prior to making the final weld. Unlike previous AGR experiments, AGR-5/6/7 incorporated epoxy only, rather than epoxy-filled metal transition cups, to make the connection between hard cable and soft extension wires. This was apparently the same failure mechanism for the four thermocouples that failed during "installation." It seems that the process of uprighting the test caused a shifting of the thermocouple cables and additional stress on the epoxy transitions. In hindsight, epoxy-filled metal cups would have been a better choice.

The nine thermocouple failures that occurred during assembly and installation were somewhat of an anomaly unique to the AGR-5/6/7 experiment; therefore, they can likely be corrected for subsequent instrumented tests without undue difficulty. The failures during operation are of greater interest. An examination of Table III reveals that of the two variables discussed above (i.e., depth in the test train, and operating temperature), depth has probably been the more dominant factor. For example, the operating temperature of capsule 2 is only a little higher than capsule 4 ; yet it suffered a $62 \%$ failure rate in operation, while none of the capsule 4 thermocouples failed during the first four cycles of operation. Capsule 1 also experienced a high rate of failure, even though all of the Type $\mathrm{N}$ thermocouples in this capsule had operating temperatures below $1000^{\circ} \mathrm{C}$ (all but one were CAMB Type $\mathrm{N}$ ).

Three CAMB Type N TCs operated at temperatures above $1150^{\circ} \mathrm{C}$. Two failed open circuit fairly early in the campaignTC-3-6 and 3-7. They operated at about $1160^{\circ} \mathrm{C}$ and $1180^{\circ} \mathrm{C}$, respectively, and failed during the second full cycle during an unplanned reactor outage after approximately 62 days of full temperature operation. On the other hand, TC-3-13 has been the control thermocouple for capsule 3 through the first four cycles and has operated successfully at approximately $1160^{\circ} \mathrm{C}$ for 155 full temperature days.

In comparing the performance between the CAMB Type $\mathrm{N}$ and HTIR-TCs installed in the hot locations of capsules 1 and 3, it is clear that the HTIR-TCs survived at a higher rate (even though the HTIR-TCs were installed in higher temperature locations).

An apparent anomaly in Table III is the observation that the four standard Type $\mathrm{N}$ thermocouples in capsule 3 all survived the four cycles of irradiation. The graphite holder in capsule 3 was made in two sections (see Fig. 3 where the outer layer is being slid over the inner layer containing the fuel) and the standard Type $\mathrm{N}$ were installed in the outer section, which runs at a much cooler temperature $\left(<800^{\circ} \mathrm{C}\right)$, and so the survival of these thermocouples was not surprising.

Fig. 4 is a comparison of thermocouple failure trends in AGR-5/6/7 to previous AGR experiments. We note that AGR-2 experienced a modest initial rate of failure, which rapidly accelerated at the end of that test; therefore, the final cycle was run with no functioning thermocouples. In this situation, the thermal model is used to determine an appropriate gas mix for 
temperature control. The AGR-1 trend line indicates a $50 \%$ failure rate. However, this is not a clear picture of the overall thermocouple performance in this experiment. The top capsule had five thermocouples - none of which failed. This represented more than half of the surviving population. The lower three capsules in AGR-1 (e.g., capsules 1, 2, and 3) were irradiated without functioning thermocouples for the last seven cycles (out of a total of 13 cycles). AGR-3/4 had good thermocouple performance. These were standard Type $\mathrm{N}$ and only $1 \mathrm{~mm}$ diameter, but they operated at lower temperatures$500-700^{\circ} \mathrm{C}$ for the most part - and the irradiation period was considerably shorter. AGR-5/6/7 has experienced a much higher failure rate during the early phase of irradiation than the previous three experiments. This is partly a function of a much higher percentage of the thermocouple complement being placed in the lower and hotter capsules. However, because of the large initial complement, all capsules had at least three functioning thermocouples at the end of cycle 164B in January 2019, which is about one third of the projected irradiation period.

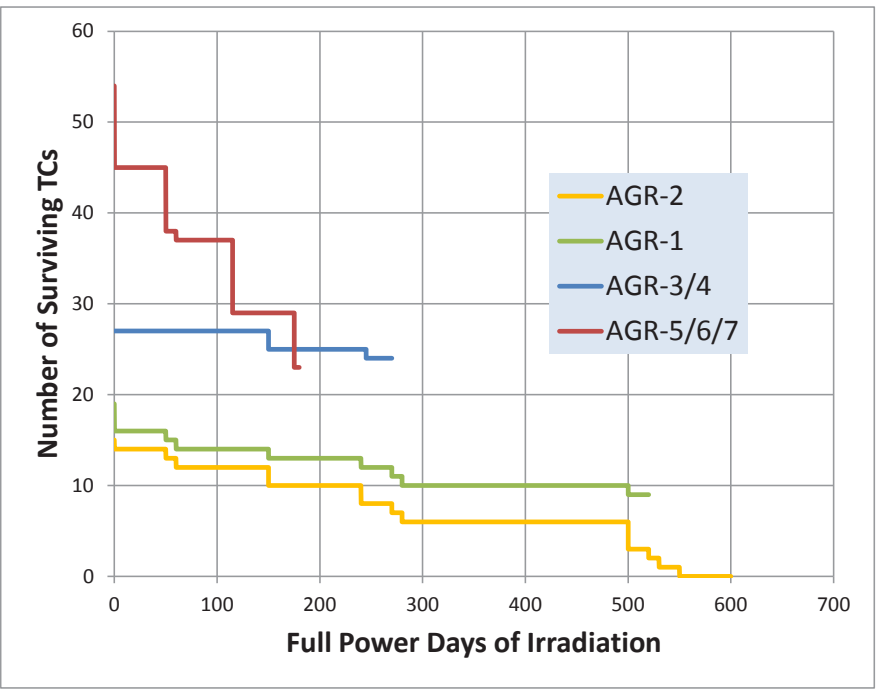

Fig. 4. Thermocouple failure trends for AGR-1, AGR-2, AGR-3/4, and AGR$5 / 6 / 7$

\section{B. Initial Accuracy}

All Type $\mathrm{N}$ thermocouples for AGR-5/6/7 were fabricated to ASTM E235 specifications. This standard requires calibration checks at 100,232 , and $419^{\circ} \mathrm{C}$. ASTM E235 is written around light water reactor applications, and thus, the calibration temperatures are relatively low. Because these Type $\mathrm{N}$ thermocouples were to be operated at much higher temperatures than envisioned by E235, samples from all lots of Type $\mathrm{N}$ thermocouples that were used in the test were spot-checked against Type $\mathrm{B}$ reference thermocouples at $1050^{\circ} \mathrm{C}$ for standard Type $\mathrm{N}$ and $1250^{\circ} \mathrm{C}$ for CAMB Type $\mathrm{N}$. The results of these spot checks are provided in Table IV.

Table IV provides evidence that the initial lot accuracy of all Type $\mathrm{N}$ thermocouples at these elevated temperatures was very good, and substantially exceeded ASTM 230 standard limits of $0.75 \%$. Table IV provides evidence that the initial readings from the Type $\mathrm{N}$ thermocouples were likely quite accurate.
Each HTIR-TC was individually calibrated against a Type B reference thermocouple, and a unique fifth order calibration TABLE IV

LOT CALIBRATION RESULTS FOR TYPE N THERMOCOUPLES IN AGR-5/6/7

\begin{tabular}{|c|c|c|c}
\hline \hline $\begin{array}{c}\text { TC Type } \\
\text { and Lot No. }\end{array}$ & $\begin{array}{c}\text { Check Temp } \\
\left({ }^{\circ} \mathrm{C}\right)\end{array}$ & $\begin{array}{c}\text { Deviation } \\
\left({ }^{\circ} \mathrm{C}\right)\end{array}$ & $\begin{array}{c}\text { Deviation } \\
(\%)\end{array}$ \\
\hline STD Type N Lot \#660 & 1050 & 2.6 & 0.248 \\
\hline STD Type N Lot \#565 & 1050 & 1.6 & 0.156 \\
\hline STD Type N Lot \#645 & 1050 & 1.8 & 0.178 \\
\hline CAMB N Lot \#504 & 1250 & 0.2 & 0.013 \\
\hline CAMB N Lot \#613 & 1250 & 2.1 & 0.166 \\
\hline \hline
\end{tabular}

curve was produced for each HTIR-TC. Although all HTIRTCs were calibrated against Type B reference thermocouples, to date, the EMF output of this thermocouple type has not been as repeatable as Type N. Furnace testing has shown that initial accuracy can be as much as $2 \%$ off [9].

Fig. 5 shows calculated temperature contours for capsule 1 during the first few days of the first irradiation cycle, after all capsules were brought to full temperature, and the locations of some of the thermocouples installed in this capsule.

In capsule 1, thermocouples TC-1-1 through TC-1-8 are CAMB Type N, while TC-1-9 through TC-1-17 are HTIR-TCs. In Fig. 5, it can be seen that the calculated temperatures for the Cambridge design were within $1^{\circ} \mathrm{C}$ of each other $\left(1080^{\circ} \mathrm{C} / 1181^{\circ} \mathrm{C}\right)$, but the measured temperatures were all more than $100^{\circ} \mathrm{C}$ lower than the calculated temperatures. Note that there is also considerably more scatter in the measured vs

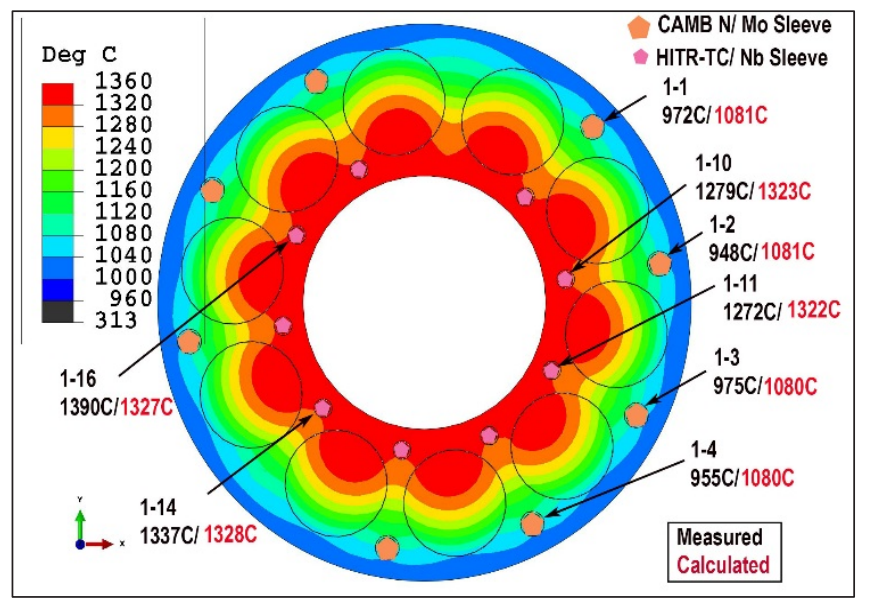

Fig. 5. Measured vs calculated temperatures for capsule 1 early in first irradiation cycle.

calculated temperatures. There is, however, no reason to doubt these measured temperatures this early in their service life, and so this comparison says more about the difficulty of accurately calculating temperatures in a fueled experiment than about the accuracy of the thermocouples (see discussion under "Drift" later in this paper). For the HITR-TCs on the right side of the figure, the calculated temperatures exceed the measured values, while the opposite is true on the left side of the figure (measured exceeds calculated). The maximum difference between the measured and calculated values for the HTIR-TCs is $63^{\circ} \mathrm{C}$, with the average difference of $43^{\circ} \mathrm{C}$, or about $3 \%$ of reading. It can be said that the measured temperatures of the HTIR-TCs are in 
reasonable agreement with the calculated temperatures, but no absolute measure of accuracy can be inferred from this comparison.

Fig. 6 shows the calculated temperature contours of capsule 3 for the first few days of irradiation after achieving full power. Shown in the figure are three Cambridge Type N (3-7, 3-13, and 3-15) and three HTIR-TCs (3-5, 3-12, and 3-14). The three CAMB Type $\mathrm{N}$ thermocouples are in good agreement with each other (i.e., within $7^{\circ} \mathrm{C}$, as they should be according to the thermal model). Thermocouples 3-13 and 3-14 are worth examining together. This is the only place in the test where a Cambridge Type N and a HTIR-TC are next to each other and the calculated temperatures are essentially the same (i.e., $1185^{\circ} \mathrm{C}$ vs. $1182^{\circ} \mathrm{C}$ ). In this case, the measured readings are $44^{\circ} \mathrm{C}$ different, with one being higher and the other lower than

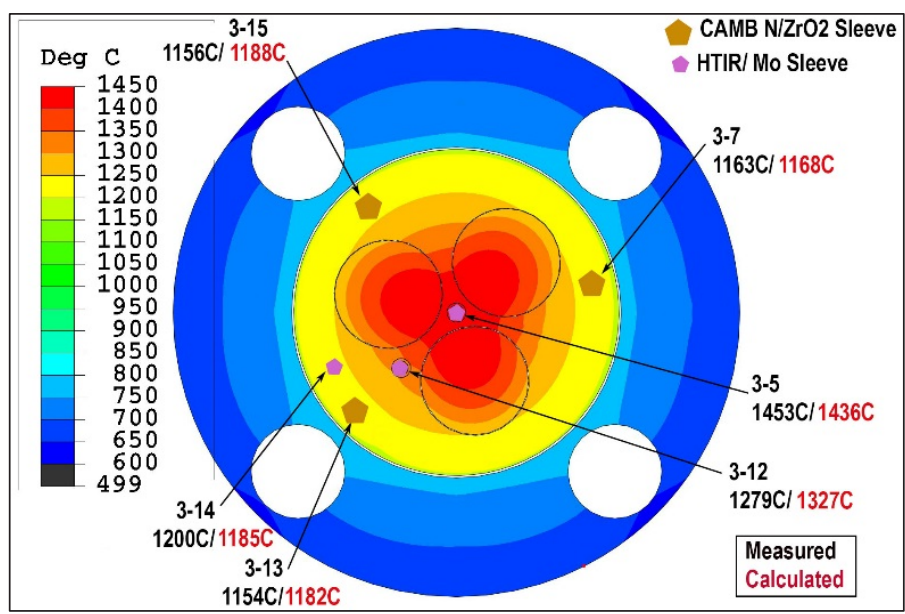

Fig. 6. Measured vs Calculated Temperatures for Capsule 3 Early in First Irradiation Cycle

the calculated temperatures. Again, the overall picture of this situation is that the calculated temperatures offer a rough confirmation of initial accuracy of the developmental HTIRTCs.

Thermocouple 3-5 measures the highest temperature in the test. The match between the calculated and measured values is quite good, with the measured value coming in at $17^{\circ} \mathrm{C}$ higher than the calculated one (e.g., an agreement within 1.2\%). This may be compared with the next hottest thermocouple in this capsule, $3-12$, where the measured value is almost $50^{\circ} \mathrm{C}$ lower than that calculated. The upshot of this is that the measured temperature gradient between TCs $3-5$ and 3-12 is considerably greater than that calculated (e.g., $174^{\circ} \mathrm{C}$ vs $109^{\circ} \mathrm{C}$ ). The graphite conductivity is possibly less than that estimated in the model. The graphite holder is made from IG-430, and changes in graphite conductivity are known to be dramatic in the first few tenths of a DPA [14].

\section{Drift}

Long-term thermocouple drift in high-temperature reactor experiments arises from two sources: (1) from thermal effects (as described earlier in this paper); and (2) from nuclear effects (primarily due to transmutation from thermal neutron absorption). Drift due to thermal effects is strongly related to temperature. The standard Type $\mathrm{N}$ thermocouples in
AGR-5/6/7 have all operated at temperatures less than $950^{\circ} \mathrm{C}$; therefore, drift due to thermal effects should be minimal. The maximum operating temperature for CAMB Type $\mathrm{N}$ in AGR-5/6/7 has been $1180^{\circ} \mathrm{C}$. The test program for this thermocouple type found no drift at $1075^{\circ} \mathrm{C}$; at $1250^{\circ} \mathrm{C}$, the drift was fairly consistent at $2.5^{\circ} \mathrm{C} / 1000 \mathrm{hrs}$. At temperatures of $1180^{\circ} \mathrm{C}$ and below, very little drift would be expected for CAMB Type $\mathrm{N}$ due to thermal effects, especially over this limited time period. Drift due to nuclear effects is also expected to be quite low for the Type $\mathrm{N}$ thermocouple Type, considering the relatively low thermal neutron dose accumulated over the first four cycles of operation $\left(<3.0 \mathrm{E}+21 \mathrm{n} / \mathrm{cm}^{2}\right)$.

For the HTIR-TCs, the expected drift discussion is more nuanced. Like the Type $\mathrm{N}$ thermocouples, the drift due to nuclear effects at the relatively low dose received in the first four cycles is expected to be minimal. However, unlike the Type $\mathrm{N}$ thermocouples, downward drift on the order of 30 or $40^{\circ} \mathrm{C}$ was expected for HTIR-TCs operating above $1300^{\circ} \mathrm{C}$ based on results from the furnace testing program [9]. This is because the heat treatment temperature was conducted at $1450^{\circ} \mathrm{C}$ (to avoid embrittling the $\mathrm{Nb}$ sheaths).

Having reviewed the expected drift, we move to the observed drift. Long-term thermocouple drift is difficult to directly quantify in a reactor experiment without resorting to elaborate means, such as incorporating a quantity of pure metal near the thermocouple junction (called a fixed-point cell) [13]. In the absence of such an arrangement, one might assume that drift could be identified by comparing thermocouple measurements to a detailed finite element thermal model. However, as alluded to in the previous section, this approach has its own weaknesses.

An irradiation experiment is a dynamic environment with many variables in play. The overarching difficulty is the large heat flux from the fuel flowing outward to the ultimate heat sink of the reactor coolant. This large heat flux creates steep temperature gradients in the graphite fuel holder (as shown in Fig. 5 and Fig. 6). Second, graphite changes conductivity dramatically under irradiation, which make these steep temperature gradients difficult to calculate accurately. Third, graphite shrinks under irradiation, changing the clearances, and hence, the temperature differences between various components. Fourth, because there are clearances between objects in the capsules, small shifts in relative position are possible: holder relative to shell, fuel relative to its channel, and even thermocouple relative to its hole (as it moves up and down from thermal expansion). Positional shifts during irradiation between the various components can result in significant differences in temperatures between the components. Fifth, the fuel compacts power down over time, which changes the solid body temperature gradients and affects the temperature drops 
across the clearance gaps between the various components. Sixth, apart from burn up, the volumetric heat generation rate from the fuel is difficult to calculate exactly because each ATR core loading is different (being a mix of used and new assemblies), and the complex interaction of reactor control elements needed to keep power constant during the cycle affects the local neutron flux, and hence, the fuel heat rate. The thermal model attempts to account for most of these factors (e.g., fuel heat rate changes, graphite conductivity change and shrinkage), but there are substantial uncertainties in each of these factors; other factors, such as components shifting relative to each other, are not accounted for at all [14]. Therefore, tracking the temperature difference of two thermocouples as a means of identifying drift, is a useful exercise, but not completely reliable.

As discussed previously, the HTIR thermocouples were only heat-treated and calibrated to $1450^{\circ} \mathrm{C}$. The current thinking is that $1600^{\circ} \mathrm{C}$ fully stabilizes the HTIR-TC. Thus, it was postulated that $1450^{\circ} \mathrm{C}$ may not have been high enough to fully stabilize the thermoelements [9] and perhaps only a few days of stable operation of TC-3-5 would be achieved because of its high operating temperature. Note that the crystal reordering as a result of heat treatment (or high temperature operation) leads to lower EMF output, and it was expected this thermocouple would drift down after a relatively short period. However, there was no evidence of this phenomenon in TC-3-5 until much later in the irradiation period.

Fig. 7 provides temperature trends for several thermocouples in capsule 3, the margin test capsule. The locations of TC-3-5, TC-3-12, TC-3-13, and TC-3-14 are shown in Fig. 6. The difference between TC-3-5 and TC-3-13 (the control TC) gradually increased from about $300^{\circ} \mathrm{C}$ to $320^{\circ} \mathrm{C}$ throughout the first cycle (162B). During the second full cycle, this difference varied between $330^{\circ} \mathrm{C}$ to $350^{\circ} \mathrm{C}$, with $\mathrm{TC}-3-5$ reading approximately $1500^{\circ} \mathrm{C}$ for most of the cycle. A similar comparison can be made between TC-3-5 and TC-3-12 (i.e., the second highest temperature measurement in capsule 3). At the beginning of the first cycle, the difference between TC-3-5 and TC-3-12 was $175^{\circ} \mathrm{C}$ and stayed quite stable, gradually increasing to $180^{\circ} \mathrm{C}$ by the end of the cycle. During the second full cycle, the difference between TC-3-5 and TC-3-12 gradually decreased from $185^{\circ} \mathrm{C}$ to about $145^{\circ} \mathrm{C}$. These comparisons with nearby thermocouples and with the thermal model lead to the conclusion that the true temperature at TC-3-5 was likely between $1430^{\circ} \mathrm{C}$ and $1500^{\circ} \mathrm{C}$ for approximately 85 days of high flux irradiation; this likely provided a temperature reading for HTIR-TC within 30 to $50^{\circ} \mathrm{C}$ of the actual temperature (i.e., 2 to $3 \%$ of reading accuracy). We believe this represents the highest temperature any thermocouple has operated without significant drift in a high neutron flux environment.

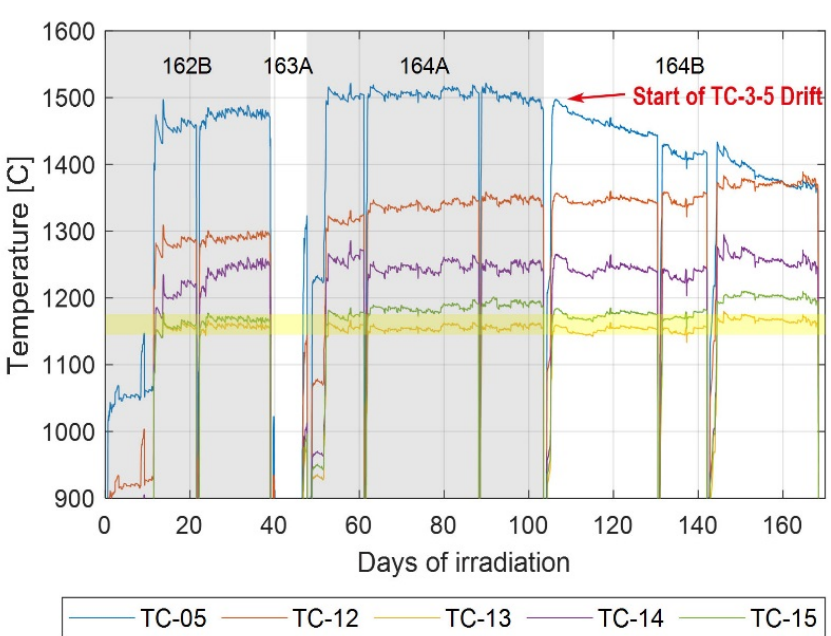

Fig. 7. Capsule 3 selected thermocouple trends.

However, as can be seen in Fig. 7, shortly after the start of cycle 164B, TC-3-5 began drifting downward in a relatively rapid fashion. By the end of cycle 164B, TC-3-5 read less than TC-3-12, which is not physically plausible given that TC-3-5 is located in the center of a three fuel stack array, while TC-3-12 is outboard of the fuel array. The cause of this drift is unknown, but as discussed previously, may have been due to the lower than ideal heat-treatment temperature. Improvements have since been made in the heat-treatment process to allow for heat treatment at $1600^{\circ} \mathrm{C}$, which should more fully stabilize the thermoelements and may provide for longer functional operating times at temperatures in the $1400-1600^{\circ} \mathrm{C}$ range.

Although TC-3-5 was the star performer in terms of peak temperature measured in the AGR-5/6/7 experiment, several other HTIR-TCs have also performed well to date at temperatures above $1250^{\circ} \mathrm{C}$. Fig. 8 provides thermocouple trends in capsule 1 for four cycles. Over this period, TC-1-12 and TC-1-14 tracked each other quite well. During the first cycle (162B), TC-1-12 and TC-1-14 showed a constantly increasing temperature difference compared to the control thermocouple operating at a relatively steady $975^{\circ} \mathrm{C}$. This increasing temperature difference was probably a result of decreasing conductivity in the IG-430 graphite holder resulting in a larger gradient between the thermocouples outside the fuel ring vs inside (partly evidenced by both thermocouples trending in the same direction). After the first cycle, TC-1-14 has gradually trended downward from $1380^{\circ} \mathrm{C}$ to about $1340^{\circ} \mathrm{C}$, and TC-1-12 has trended downward from $1310^{\circ} \mathrm{C}$ to about $1255^{\circ} \mathrm{C}$. These similar trends provide a degree of assurance that this is likely not due to thermocouple drift, but rather an effect of the fuel compacts burning out (powering down) and resulting in a smaller temperature difference between the control thermocouple (TC-1-4) outside the fuel ring operating at a steady $975^{\circ} \mathrm{C}$, and TCs $1-14$ and 1-12, which are inside the fuel ring. 


\section{REFERENCES}

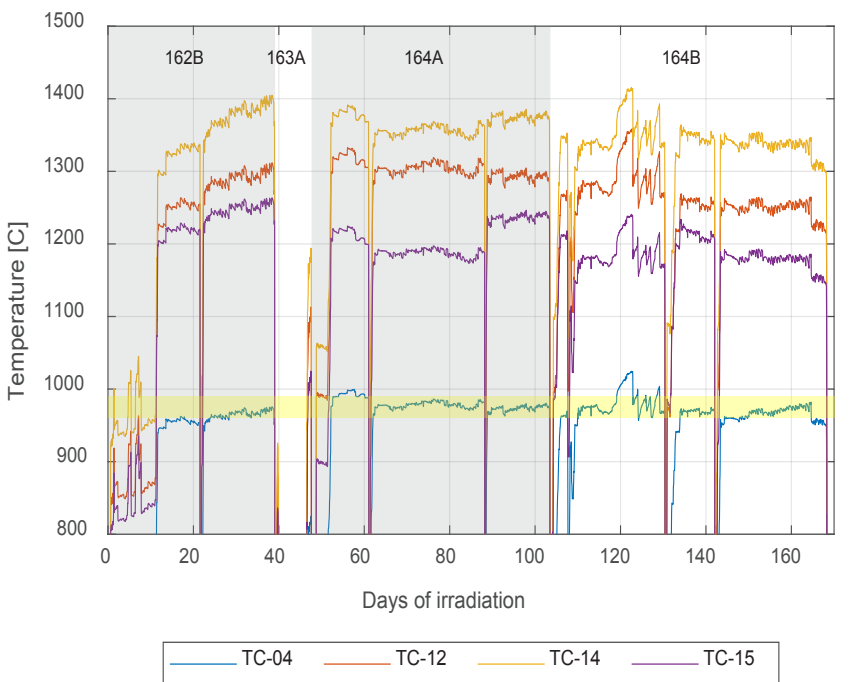

Fig. 8. Capsule 1 selected thermocouple trends.

\section{CONCLUSIONS}

1. Because of the high operating temperature of the AGR-5/6/7 experiment, a large number of thermocouples were incorporated into the test. In the lower three capsules, the failure rates have been even higher than expected ( $>60 \%$ ) during the first four operating cycles. However, all capsules had at least three operating thermocouples at the end of this period.

2. HTIR-TCs survived better than the CAMB Type $\mathrm{N}$ in the most severe locations in the experiment. However, one CAMB Type $\mathrm{N}$ operated at $1160^{\circ} \mathrm{C}$ for 155 days without apparent drift.

3. One HTIR-TC operated at $1450-1500^{\circ} \mathrm{C}$ for 85 days without observable drift, which we believe to be the highest sustained temperature ever recorded in a reactor experiment. Three other HTIR-TCs operated at 1250$1400^{\circ} \mathrm{C}$, also without observable drift.
[1] A. J. Palmer, D. A. Petti and S. B. Grover, "Advanced Gas Reactor (AGR)-5/6/7 fuel irradiation experiments in the Advanced Test Reactor," in Proceedings of ICAPP 2014, Charlotte, NC, USA, April 6-9, 2014, Paper No. 14017.

[2] M. J. Kelly, W. W. Johnston and C. D. Baumann, "The effects of nuclear irradiation on thermocouples," in Temperature Its Measurement in Science and Industry, 1962, pp. 265-269.

[3] J. D. Heckelman and R. P. Kozar, "Measured drift of irradiated and unirradiated W3\%Re/W25\%Re thermocouples at nominal $2000 \mathrm{~K}$," in Temperature Its Measurement in Science and Industry, 1971, pp. 1935-1949.

[4] B. W. Washburn, "A thermocouple evaluation model and evaluation of Chromel-Alumel thermocouples for high temperature gas cooled reactor applications," LA-NUREG-6768-MS, 1977.

[5] M. Scervini, C. Rae and B. Lindley, "Transmutation of thermocouples in thermal and fast nuclear reactors," in Conference Proceedings of ANIMMA 2013, June 23-27 2013, Marseille, France, pp. 1-8.

[6] J. L. Rempe, et al., "Thermocouples for high-temperature in-pile testing," Nucl. Technol., 156, pp. 320-331, Dec. 2006.

[7] J. L. Rempe, et al., "Long duration performance of high temperature irradiation resistant thermocouples," in Proceedings of ICAPP 2007, Nice, France, May 2008.

[8] R. S. Skifton, A. J. Palmer and P. Calderoni, "Optimization of heat treatment and calibration procedures for high temperature irradiation resistant thermocouples," Instrum. Sci. Technol., 46, pp. 349-363, Dec. 2017.

[9] A. J. Palmer, et al., "Development and testing of thermocouples for the Advanced Gas Reactor fuel experiment AGR-5/6/7," in Proceedings of NPIC and HMIT 2019, Orlando, FL, USA, Feb. 9-14, 2019, Paper No. 25978.

[10] M. Scervini and C. Rae, "Low drift type N thermocouples for nuclear applications," in Conference Proceedings of ANIMMA 2013, Marseille, France, June 23-27, 2013, Paper No. 1054.

[11] A. J. Palmer, et al., "Summary of thermocouple performance during Advanced Gas Reactor fuel irradiation experiments in the Advanced Test Reactor and out-of-pile thermocouple testing in support of such experiments," in Conference Proceeding of ANIMMA 2015, Lisbon, Portugal, April 20-24, 2015, Paper No. 51.

[12] The Temperature Handbook, Fifth Ed., Omega Engineering, Inc., p. H-7, 2004.

[13] M. Laurie, et al., "New fixed point mini-cell to investigate thermocouple drift in a high-temperature environment under neutron irradiation," in Conference Proceedings of ANIMMA 2015, Lisbon, Portugal, April 20-24, 2015, Paper No.

[14] G. L. Hawkes, et al., "Thermal Predictions of the AGR-3/4 Experiment with Post Irradiation Examination Measured TimeVarying Gas Gaps," ASME J. Nuclear Rad. Sci. 3(4), 041007 (Jul 31, 2017), Paper No: NERS-17-1008; doi: 10.1115/1.4037095. 